\title{
A clinical model for decision-making
}

\author{
Richard M Martin Medical College of Georgia, United States
}

Richard Martin's aim in this paper is to present a critical method of making ethical decisions in a medical context. He feels that such a reflective method provides the best means of making the appropriate decisions in given situations. It is based on $\mathrm{Dr}$ Martin's experience in applying ethical theory while collaborating with physicians in the daily course of clinical practice. Through his giving of a functional definition of medical ethics, his descriptions of an analytical model, the significance of values for clinical decision-making and the advocacy role of medical ethicists and their relationships with clinicians, Richard Martin sets out his own value-intention as regards an ideal decision process. He stresses that his argument is of particular importance to his fellow ethicists who should continuously and vigorously examine the creative interaction of faith and fact in their own inquiry and action. Dr Martin concludes by stating that physicians and ethicists can work together to accomplish their common aim, which is, of course, the health and well-being of the patient.

John Dewey traces the development of Western ethical thought in terms of what he calls a revolutionary assertion 'that conduct is not truly conduct unless it springs from the heart, from personal desires and affections, or from personal insight and rational choice'. ${ }^{1}$ The custom-directed morality of a more ancient, homogeneous world has given way to a more reflective, rationally critical approach demanded by a new world filled with incompatible values and unprecedented issues. In the place of the definitive casuistry of the old customary morality, this reflective morality offers assistance in making personal choice more intelligent. According to Dewey, it enables an individual to place his moral conflicts into the larger context of general types and intellectual precedents and make his 'personal reflection more systematic and enlightened, suggesting alternatives that might otherwise be overlooked, and stimulating greater consistency in judgement'.1 Reflective morality does not seek to overcome the necessity of personal choice with ready-made answers; it facilitates it. This development constitutes, in William Frankena's words, a 'move from a rather irrational kind of inner direction to a more rational one in which we achieve an examined life and a kind of autonomy, become moral agents of our own, and even reach a point when we can criticise the rules and values of ou? own society ...'2

The medical context of ethical decisions is, course, in flux. It is hardly a novel idea that most o our easily accessible moral answers have been made obsolete by the rapid development of technologis and the proliferation of its products. In fact, this decline of moral certainty in the face of the biotechnical revolution is a favourite lament of many writers. However, if Dewey and Frankena are to b $\vec{e}$ taken seriously, the decline is consonant with man'\$ coming of age morally, so to speak, and should b£ met with enthusiasm, not lamentations. The new iconoclastic occasions which unsettle old moraథ conclusions are stimulants to the reflective minto equipped with a critical ethical method.

This paper presents such a critical method. It has been written because ethical decisions made in the medical context are important and a reflective method provides the best means for making appro윰 priate ones. It is hoped that the method will helpo facilitate intelligent personal choice or, at the very least, prod the reader into public discussion of $\overrightarrow{\mathrm{a}}$ better one. The description of the method wilP consist of:

I) A functional definition of medical ethics as the analysis of decision in action and the advocacy of certain human values,

2) A critical model for that analysis,

3) A description of the significance of values for clinical decision-making,

4) The advocacy role of medical ethicists and theie interrelationships with clinicians.

It is based on the writer's experience in applying ethical theory while collaborating with physicians in the daily course of clinical practice in the wardso of the Departments of Medicine and Neurology an the Medical College of Georgia.

\section{A definition of medical ethics}

In a recent book edited by Irving $S$ Cooper and others, Harmon Smith states that, ' $[\mathrm{t}] \mathrm{o}$ examine life in terms of the values which support and inform it ${ }_{\vec{D}}$ is to practise ethics'. ${ }^{3}$ Smith goes on to suggest two points which are important to the concept of ethicap theory to be presented here: ethics is 'characterised? by a spirit of radical inquiry' into moral value as an essential element of human action; and such inquiry 
is profitably exercised by comparative analysis of 'belief and behaviour', that is, by asking if an action is appropriate for the agent's values and intentions. ${ }^{3}$

The spirit of radical inquiry basic to ethics provides an epistemological approach which can help to make decisions more systematic and enlightened in several ways. It helps to identify and define the issues that are important to those who must decide and, thereby, focus their attention on them. It exposes the process of decision-making, itself, and provides a clearer understanding of its structure, its component parts and the character of their dynamic interaction. Critical analysis stimulates inquiry and offers a model by which most that is significant, both in the context and for the inquirer, is brought to light, and by which the consequences of the decision in action may be honestly evaluated. Ethics makes its special contribution to reflection by exposing the significance of his own value complex to the decision-maker and providing him access to the norms and principles which support and inform his decisions.

One way that ethics makes this special contribution is illustrated by Smith's suggestion that the inquiry is an assessment of the 'coherence and comprehensiveness between ... character and conduct, belief and behaviour, affirmation and action'. ${ }^{3}$ Ethical reflection presupposes that each decision in action is an expression of an ideological intention. It represents the momentary fulfilment of a moral ideal which, because of the inescapable complexity of situation and value structures, is, itself, incomplete and ambiguous. An important function of a critical ethical theory is to ask if this momentary expression is, indeed, a fulfilment of the ideal, that is, if it fits with the moral intention in its substance and consequence. It asks if the decision in action is appropriate for the ideological purposes of the agent. In the course of this assessment of appropriateness, the rigorous inquiry contributes to a critical awareness of the moral ideal, itself. The nature and function of general principles are examined along with their more specific constituent rules and codes. Ethics asks questions such as what principle is the standard for the decision? Why is it given priority over others? Is the rule system coherent and consistent with the implications of the principle? Exposed in such a way, even basic moral values, themselves, are made the subject of analysis and criticism.

It is important for any definition of ethics to note that the rigorous character of this inquiry requires universal application of its intensive analysis. All categories of human decision are to be assessed by the same standards. In fact, the critical intention of ethics demands that even its own motivating and informing sources be explored. Of what value is all this intensive inquiry? Why is reflection preferable to custom? After all, it is a painstaking task that people normally avoid, prefering a kind of moral $\frac{m}{5}$ reflex based upon an intuitive feel for the 'right thing' which seems to be universally available. $\overrightarrow{\vec{F}}$

The answer to such questions reveals a telling $\stackrel{\text { ? }}{+}$ point about ethics. As is true of every category of $\frac{}{0}$ human reflection it subjects to analysis, ethical $\frac{\bar{\omega}}{\bar{D}}$ inquiry is motivated and sustained by ideological $\frac{5}{\vec{D}}$ intentions, that is, it serves certain human purposes $\varrho$ and moral values. When ethicists are asked why the $\%$ decisions of physicians should be so rigorously $\vec{\circ}$ examined, we respond with Frankena and Dewey that it is necessary because mere moral reflex is $\vec{\omega}$ inadequate for the complexities of our contexts of decision. For example, we argue that all the new possibilities created by advancements in medical $+A$ technology have made the simpler, more custom- it oriented sorts of decision-making obsolete; or that $\mathbb{O}$ the immense significance of the decisions of $\mathrm{O}$ physicians for the lives of their patients demands the most serious kind of deliberation. We maintain $\vec{\nabla}$ adamantly that less desirable ways of deciding not $\mathbb{D}$ only do not work well enough, are inadequate, but $\stackrel{\Phi}{乛}$ that they probably are morally suspect. This paper makes it apparent that I generally agree with these $\stackrel{\mathbb{Q}}{-}$ arguments. I believe in the examined life, rigorous $\vec{\theta}$ ethical inquiry, and the other tenets of the ethicist's $\infty$ faith. It is for me a means of fulfiling certain 0 normative ideals, certain principles and moral values which make sense of $m y$ universe and direct the course of $m y$ action.

This affirmation is important, not only as a $\frac{\mathrm{D}}{\mathrm{D}}$ confession of faith, but because it demonstrates an essential element in a functional definition of ethics: ethics is practised by ethicists who are no less affected by their own motives, purposes and commitments than other mortals; or, perhaps more appropriately put, ethicists also enjoy the benefits of meaning and direction provided by their values. $\frac{\Phi}{\circ}$ Ethical analysis provides us with the means for 3 . advocacy of those values and ideals which inform us about our lives and support the decisions we make. Ethical theory is morally significant because it helps $\mathrm{O}$ to reveal our normative intentions and the means by which our ideals can be fulfilled in action.

\section{An analytical model}

With this definition of ethical theory in mind, the $\omega$ description of a decision model may be presented which serves this dual function of analysis and $\stackrel{0}{D}$ advocacy. The reader who is familiar with the Christian ethical theory of Waldo Beach will recognise the strong influence of his schema for 0 'double contextualism' upon the graphic represen- $\mathbb{D}$ tation. It should be added that the writer has revised $\frac{?}{\mathbb{D}}$ and elaborated his schema in order to emphasise $\frac{\varrho}{\sigma}$ certain elements which are of particular importance in the medical context. The most significant 8 suggestions for this revision and elaboration came 
from Max Weber's Verstehen methodology, particularly his discussions of the role of value-orientation. ${ }^{4}$

This analytical model is based upon the principle that the optimal decision is one which is appropriate for both the objective context and the evaluating subject. It is optimal because it recognises the inevitable interplay between what one supposes to be the actual circumstances, viable options and probable consequences, and his own value-laden approach to facts. A theory based upon that principle affords a rigorous system by which every element of significance to decision might be examined. Figure I will be used to help demonstrate a model of this system.

The interaction in decision-making includes, first of all, an objective context, a complex of observed phenomena. This object is composed of a conglomeration of things, places and episodes of human behaviour, some of which represent some sort of recognisable interrelationship, many of which seem not to be connected at all. These are the data which we might refer to as facts (Fig. I.I). They are bits of information which we observe or have reported to us about what is happening and recognise as being somehow important for understanding the event who is involved, where, when and how the events proceed. These data constitute much of the empirical knowledge available to the decision-maker, the collection of things and events to which he ascribes meaning and in the face of which he acts.

The objective information also includes the values at stake in the observed interactions (Fig. I.2). The factual events occur as human beings make decisions and act to fulfil their own moral ideals, their own intentions. In order to take full account of the available empirical information, the observer must $\vec{F}$ ask why some action-events occurred and not $\stackrel{\rho}{?}$ others? What caused, that is, motivated and directed what happened? Human agents actually $\frac{\overline{\bar{c}}}{\bar{\rho}}$ create historical events as they apply their value $\frac{\vec{\sigma}}{\vec{\sigma}}$ structures to provide meaning and direction for their $\varnothing$ world. Such value structures include, at least, each क individual's specifically personal ideology, interests $\vec{\circ}$ and desires, behavioural norms and role-expectations $\overrightarrow{-}$ prescribed by his social interrelationships, and a $\vec{\omega}$ cultural identity which provides a world view and content for his ultimate concerns. The object of $\bar{\Phi}$ analysis can hardly be understood unless the normative postulates of these human agents are treated to $\vec{i}$ the same rigorous assessment as other pertinent 8 data.

This objective context of fact and values at stake is significant for the act of decision because it $\vec{\nabla}$ enters into an epistemological and normative inter- $\mathbb{D}$ action with the decision-maker. This evaluating $\mathbb{\triangle}$ subject contributes his intellect to the process of datao assessment (Fig. 1.3). The decision-maker possesses $\stackrel{\mathbb{}}{-}$ a rational ability, that is, he is capable of mentally $\vec{\theta}$ processing data by using concepts and organising 0 them into manageable patterns. He has cultivated this rational ability even further by providing it with more refined and directive concepts and models through some specific training. This intellectualo aspect of the evaluating subject is shaped and으 focused by patterned exercise so that it can make exclusive abstractions from the overwhelming mass윽

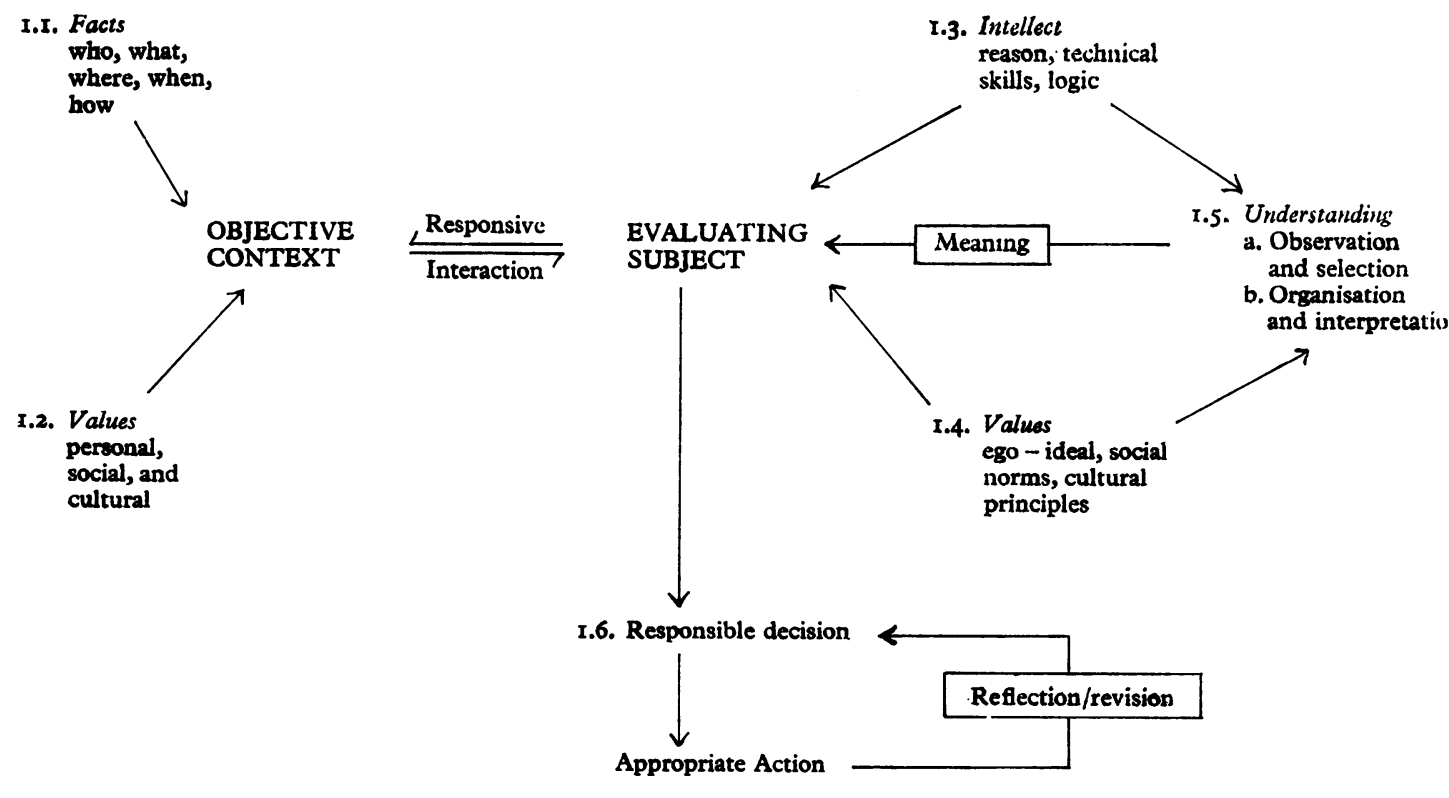

Fig I The structure of decision and action. 
of experiential data and make sense of his world with ideal constructs. He approaches the object with his own particular rationality, special technical skills and logic.

As the term implies, the evaluating subject also possesses his own value structures (Fig. I.4). They determine his concern, approach and management of the objective context. He comes to the context with a cause supported and informed by an ego ideal, that is, his own understanding of what he is and ought to be, by social rules, roles and norms, and by moral and philosophical principles which characterise his culture.

This intellect-value complex makes action possible by making sense of the objective data and providing form and content for action. The moral intention of the subject-values distinguishes certain relevant data as significant and the subject-intellect creates conceptual patterns useful for fulfilling that intention. Without these the object would remain a chaos of uninteresting, unimportant and useless data.

To make decisions, then, the evaluating subject must interact with the data to help create the object and formulate an appropriate course of action. $\mathrm{He}$ must understand the data and what it means for his moral ideal (Fig. 1.5). The interest of the decisionmaker is first expressed in his recognition that he is confronted by a situation that either threatens his moral ideal or gives him an opportunity to fulfil it. As this general sense of concern develops, he proceeds to more specific assessment of the occasion by selecting those data which his concern, purpose, and previous experience determine to be significant, that is, useful. In essence, he pursues his ideal by a process of unilateral selection, and the significance and meaning he finds in events are based upon his own value-orientation. $\mathrm{He}$, then, organises the data into familiar conceptual patterns which he creates by purposeful abstraction, the construction of heuristic concepts, and the use of conventional assumptions of proximate causation. Having reduced the plethora of data to manageable proportions and bestowed order to an otherwise chaotic collection of dissociated events, the subject can convert the information into useful knowledge for practical decision (Fig. 1.6). At last, he is ready to act. This interpretation for action occurs as he assesses his portrait of the context, its constraints and possibilities for fulfilment, and formulates a response which will take greatest advantage of the perceived situation. As the consequences of his decision begin to become apparent, he enters a continuing process of reflection upon its actual efficiency. By this reflection, he tries to determine if his expectations and intentions are being realised and whether or not his creative understanding or tactics might need to be revised. He asks questions about cost and benefit for his ideal, about how well his own action answers the threat or maximises the opportunity for manifesting his moral ideal, his 'good'.
This description of the process of decision for action is presented not only because decision seems to function that way, but also because it contains certain elemental considerations which ought to be taken into account in ethical theory. It is based upon the idea that a decision should be responsible to both context and moral ideal, that is, that it should be appropriate for an object which includes facts about observable events and value-orientations which help to create the events, and for an evaluating subject who is a complex of intelligence and valueaffirming intention and is at once struggling to maintain familiar manifestations of his moral ideal and to advance toward its ultimate fulfilment.

The significance of values for clinical decision-
making

If this model is applied to the clinical decisions physicians must make, it become obvious that they are involved in the same creative, evaluative process even within the narrow limits of their practice. Their decision-making process also helps to demonstrate this abstract model with more specific clarity. Figure 2 illustrates their clinical decisions.

The object in which the physician finds his limitations and possibilities usually has to do with a patient in his context. The physician meets his facts in the form of a bundle of symptoms such as pains or confusion and/or signs such as an abnormal reflex or high blood pressure in a history of physical and social complaints, in a physical examination, etc., (Fig. 2.I). In spite of the fact that the scope of available data is limited to the general area of an individual's health problems, the amount of information that the concern of the patient, the skill of the clinician, and the wonders of medical technology can in concert create, is considerable.

In his interrelationship with the physician, the patient exercises a multitude of individual interests. $\mathrm{He}$ is concerned about more needs, problems and opportunities than, for example, his backache. He has moral and religious structures which greatly influence the meaning of his pain and what he will $\frac{D}{O}$ do to resolve it (Fig. 2.2). He has a particular world view and philosophy of life by which he understands $N$ his own being and ultimate reality. The physician is confronted by an acting person for whom the $N$ meaning of his illness and the significance of the $\omega$ physician have been formulated by some value-

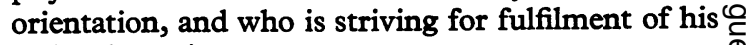
action-intention.

The physician's job is to evaluate the patient; that is, he must ascribe meaning and significance to $\frac{0}{0}$ the chaos of data presented to him and formulate $a \stackrel{\vec{D}}{\vec{C}}$ response. The understanding the physician must $\frac{\rho}{\mathrm{D}}$ have of his patient so that successful treatment may $\cong$ occur comes only when the clinician-agent wilfully? interacts with each unique patient context.

The physician's tools for making sense of clinical 


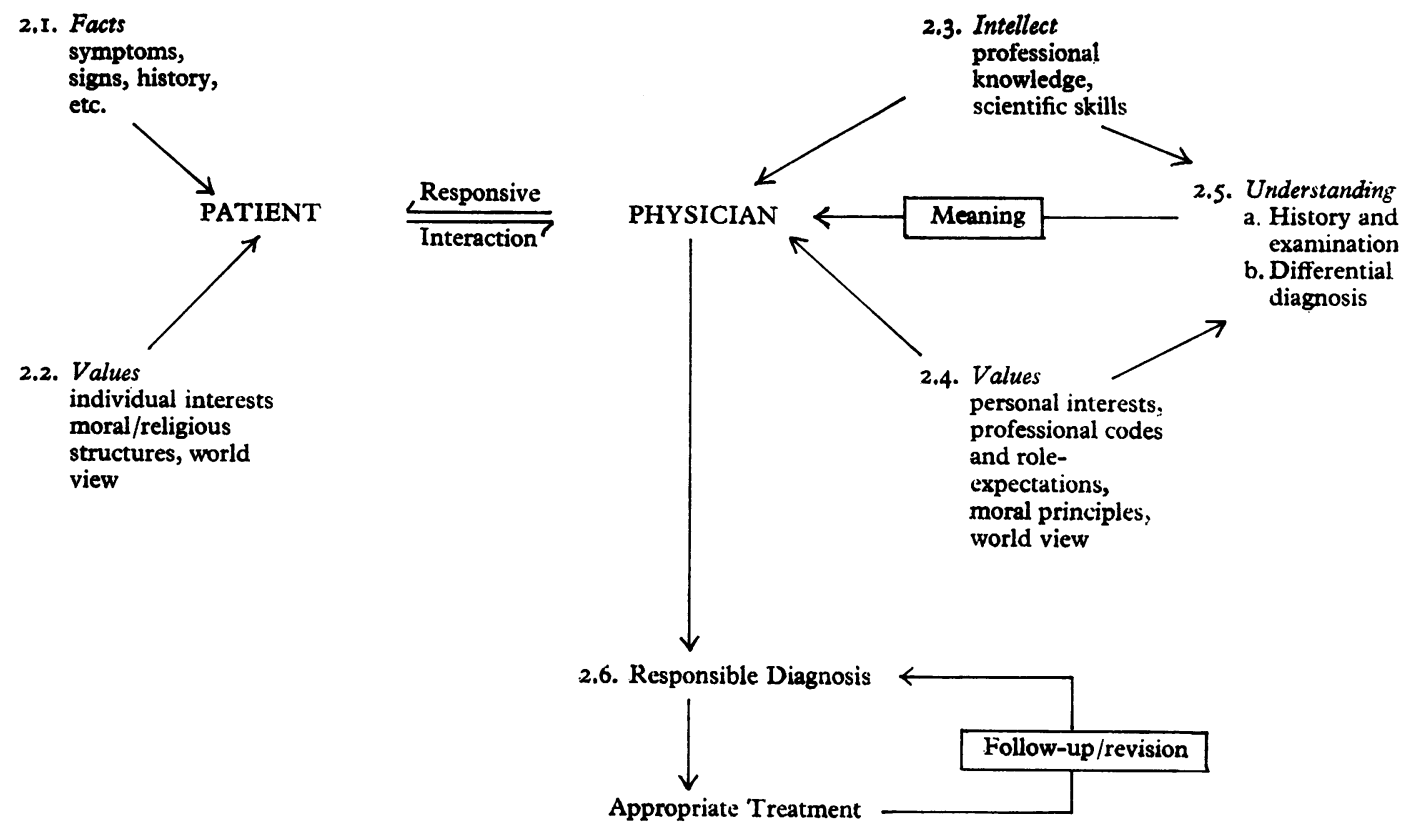

Fig 2 The structure of clinical decision and action.

data include, obviously, a highly developed intellect (Fig. 2.3). The years of required education and training have provided him with professional knowledge about where the back is, what it does and what makes it hurt. He possesses a vast array of scientific skills and techniques which enable him chemically and physically to probe and repair backs and many other parts of the body. He knows names, concepts, systems, and intellectual approaches by which he can abstract, order, and manipulate data about the patient with great empirical success.

As any other evaluating subject, the physician has value-orientations to support and inform him in his work (Fig. 2.4). His own idiosyncratic interests, his personal likes, desires, and objects of affection help to provide him with an image of an ideal self and, by generalisation, the kind of person he thinks his patient ought to be. For example, he might want to help people be like he is, clean, truthful, altruistic, well-educated and articulate, healthy, and hardworking. He ascribes meaning and significance to his patient's situation according to his own criteria and goals. He is, also, a part of a set of social systems and a member of reference groups which provide him with functionally specific norms and roleexpectations. Being a physician instructs him that he is expected to exhibit active concern for illness wherever he finds it and employ all the resources at his disposal to achieve a successful resolution for every patient. His professional code of ethics demands that, above all personal interest, he devotes himself to the welfare of his patient, the general good of society, the scientific advance of medicine, and the integrity of his profession. ${ }^{5}$ His culture provides him with moral principles, religious tenets, and a general world view in a kind of superordinaten meaning-structure which helps to answer ultimateo questions of significance. These are final authorities which test the rules of fact and behaviour and byo which understanding and response are oriented and legitimated. The physician makes his final appeal for his evaluation of the patient to fundamental beliefs like the truth of the scientific method, the sanctity of the quality and extent of human life and the moral imperative of the 'golden rule'. ${ }^{5}$ Such 3 . general expressions of cultural value serve as moralo principles which are manifested in particular situations as functionally specific rules and norms, 0 and which determine priorities among competing? goods and truths. These various structures of value- 0 orientation enable the believer-physician to undertake decisive interaction with the patient because $O$ they provide defining purpose, significance for data N selection, and reflective criteria; they provide the N action-intention.

The clinical setting has its own special terms for the understanding and action process, but its basic functions remain intact (Fig. 2.5). The observation $\stackrel{\mathcal{S}}{+}$ of the patient-context and selection of significant data occur in medicine as history-taking, review of ${ }^{-}$ systems, physical examination, and laboratory tests. By these procedures, the physician submits the $\frac{O}{\mathbb{D}}$ chaos of information about the patient to a stan- $\varrho$ dardised, well-practised pattern of inquiry which is carefully designed to elicit those data which fit a 8 relatively small number of possible explanations for 
rather specific clinical problems. The physician is looking for a way to categorise these problems in terms of a familiar syndrome or disease. His first action-intention is to find a single, treatable lesion. From the moment he first meets the patient, the physician begins to organise the data into a differential diagnosis, that is, a list of likely possibilities each of which is used as a working hypothesis to guide clinical investigation. This process continues as he tests and eliminates his suspicions, and amends and reorders his differential until he is reasonably satisfied with an explanatory theory. The result is an interpretation of the patients' problems in terms of a diagnosis, the meaning of which includes something of the nature of the disease and its causal relationship with some event or agent along with a general idea of its course and outcome (Fig. 2.6). Once the diagnosis is made, the physician can prescribe the appropriate treatment according to his knowledge of conventional medical practice. The treatment will usually be one alternative among several which might range from chemotherapy to surgery, from a couple of weeks of bedrest to laminectomy. His choice may be made on the basis of what he last read, how he feels about surgeons, or his own years of experience and training. The reflection on the results of the decision, the treatment, comes in the form of follow-up during a period of relatively close scrutiny of the patient's progress. If improvement of the symptoms and signs can be seen, the patient will continue the prescribed course to completion. If there is deterioration or no improvement the treatment is changed and, in some ambiguous cases, even a new diagnosis may be sought.

The responsible decision and appropriate action for the physician requires applying his special epistemological skills and value-intention to contribute meaning and significance to the clinical data so that he may understand the objective reality of the patient and interact with its demands. Without the value-intention of the physician, the data would be mere information, unorganised, meaningless, and pointless for the purposes of decision. At the same time, the patient who confronts the physician is objectively real; he is independent, factual context without whom the physician's evaluation would be disembodied, abstract and useless. For a decision to be appropriate for this kind of interaction, the physician must use all his effort and skills to understand the patient as a particular, historical individual who creates his own world by value-intention. The physician needs to realise that the patient's valueorientations and how they support and inform him may be different from his own. Once the physician understands the character and significance of his own value-orientation and that of his patients, he can make his 'personal reflection more systematic and enlightened, suggesting alternatives that might otherwise be overlooked, and stimulating greater consistency in judgement' ${ }^{1}$ He may 'even reach the $\stackrel{\text { TI }}{F}$ point when [he] can criticise the rules and values of [his] own society' ...2

The role of advocacy in medical ethics and the
ethicist's interrelationship with clinicians

My explanation of this analytical model includes a $\frac{\mathbb{D}}{\circ}$ rather obvious statement of my own value-intention as regards an ideal decision process. It is replete with what I believe ought to be the purpose, data $\vec{\circ}$ criteria, and eventual result of action. Words like $\overrightarrow{\vec{\omega}}$ 'appropriate' and 'responsible' are not value-free $\stackrel{\omega}{\mathcal{S}}$ terms. What is at stake is my own value system, my own supposition of meaning and significance. We ethicists must never allow ourselves to forget to uncover our own unrecognised postulates. We must i rigorously examine the creative interaction of faith 8 and fact in our own inquiry and action. This critical ethical theory is important to me because it serves my advocacy for medical decisions which $\nabla_{\mathbb{D}}$ appreciate the essential function of value-orientation $\varnothing$ and the historical uniqueness of individual patients 3 and physicians, and which fulfil my own moral principles and philosophical presuppositions.

There is always some question as to whether the clinician will cooperate with the ethicist. While they may share common value structures, the ethicist's demands for critical reflection are often inconvenient and may even threaten territorial imperatives, ideal

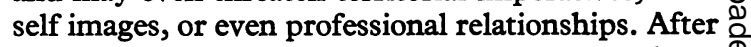
all, most clinical decisions are based upon procedures $\stackrel{\odot}{\complement}$ and expectations which enjoy extensive conventional $\overrightarrow{\overrightarrow{0}}$ authority.

The clinician makes his own demands upon those he will allow into his practice, especially people who? are not members of his profession. On a personal level, he requires that his associates stand the test $\overparen{D}$ of his own self image; that is, that they are intelli- $\frac{0}{3}$ gent, honest, hard working, and demonstrate a real concern for the needs of the patient and his own $ᄋ$ profession. On a more professional level, the clinician demands expertise, that is, that associates know their $\frac{\text { ? }}{9}$ business. He will not trust an ethicist who seems 7 inept. Finally, he requires that the expertise of any associate be applicable to the fulfilment of his own intention, that is, the successful diagnosis and treatment of his patient's problems.

The success of the ethicist's advocacy is made $N$ possible because he can contribute to an idealo clinical intention with which he can generallyo concur. Ethical theory can help provide a more $\overparen{\Phi}$ accurate understanding of clinical data about the $\stackrel{?}{+}$ patient through an appreciation of formative 0 intentions and value-orientations in that context. It $\stackrel{\vec{D}}{\vec{D}}$ can help to point out the issues and possibilities for $\stackrel{\mathbb{Q}}{\Phi}$ decision and action. Ethical theory can help clarify $\underset{\Omega}{\mathbb{Q}}$ what the physician's value-structures are like ando provide a means of systematically assessing their adequacy for fulfilling his moral ideal. It helps the응 
clinician to formulate diagnosis and treatment which are most likely to be successful, that is, achieve the best results for his patient. The ethicist has confidence that this kind of analytical assistance serves his own intention because he shares most of the physician's cultural principles and social norms; and he believes that, when these common value-orientations are fully understood and acted upon, his own moral ideal will be fulfilled. Physician and ethicists can work together to accomplish their common goal, that is, the health and well-being of the patient.

\section{References}

${ }^{1}$ Dewey, John (1974). Reflective morality and ethical theory, in Introductory Readings in Ethics, Frankena, William $K$ and Granrose, John T (eds), pp. 16, 23. Englewood Cliffs, New Jersey, Prentice-Hall Inc.

${ }^{2}$ Frankena, William (1973). Ethics. Englewood Cliffs, $\overrightarrow{\vec{S}}$ New Jersey, Prentice-Hall Inc.

${ }^{3}$ Smith, Harman C (1974). Some ethical considerations $\frac{C}{O}$ of cerebellar stimulation as an innovative therapy $\overline{\bar{n}}$ in humans, in The Cerebellum, Epilepsy, and Behaviour, Cooper, Irving S, Rikler, Manuel and $\varrho$ Snider, Ray S (eds), pp. 343-344. New York, 心

Plenum Press.
${ }^{4}$ Weber, Max (1949). The Methodology of the Social ${ }_{-}$ Science, Shils, Edward $A$ and Finch, Henry $A_{\vec{\omega}}$ (Translators). New York, Free Press.

5 Judicial Council (1958), American Medical Association, Principles of Medical Ethics, Sections I-4 and Preamble. 